\title{
Study of Thyroid Function in Patients of Srikakulam, Andhra Pradesh, Who Were Suffering from Various Depressive Disorders
}

\author{
Silla Vijaya Bhaskara Guptaํㅜㄹ. M. Padma Geetanjali², Ladi Bharati Kumari Devi ${ }^{3}$ \\ ${ }^{1}$ Department of Psychiatry, Government Medical College, Srikakulam, Andhra Pradesh India. ${ }^{2}$ Department of \\ Physiology, Government Medical College, Srikakulam, Andhra Pradesh India. ${ }^{3}$ Department of Physiology, District \\ Immunization Officer, DM \& HO Office, Srikakulam, Andhra Pradesh, India.
}

\section{ABSTRACT}

\section{BACKGROUND}

Thyroid disorder patients are more prone to develop depressive symptoms. Depression is also associated with various thyroid abnormalities. ${ }^{1}$ Slight change in thyroid hormone levels show symptoms of depression, anxiety, increasing fatigability and psychomotor slowing. The depressive symptoms are more in elderly patients with rapid changes in thyroid hormone levels. ${ }^{1}$ In depressive disorder patients, $1 \%$ to $4 \%$ have primary (Overt Hypothyroidism) and $4 \%$ to $40 \%$ have subclinical Hypothyroidism. ${ }^{2}$ Overt thyroid dysfunction is usually mild. Thyroid abnormality is not a causal factor, it is mainly a risk factor for depression. ${ }^{2} \mathrm{We}$ intended to study the thyroid function in various depressive disorder patients of Srikakulam district at Government medical college \& General hospital Srikakulam. Srikakulam district has been chosen for this study for its backwardness in the residuary state of Andhra Pradesh. The objectives were to find out thyroid function levels like serum TSH, T3 and T4 in various depressive disorder patients and compare with the severity of clinical score, analyse and correlate with various depressive disorder patients of different age and sex groups, locality (both rural and urban areas).

\section{METHODS}

This observational study of thyroid function was conducted among 61 various depressive disorder patients of both males and females of 21 to 60 years age group who attended OPD and IPD of Psychiatry, Government medical college and general hospital, Srikakulam. We analysed and correlated serum TSH, T3 \& T4 levels with various depressive disorders.

\section{RESULTS}

It was observed that subclinical hypothyroidism had a clinical severity of $16.39 \%$, overt hypothyroidism was $1.63 \%$, secondary hyperthyroidism was $1.63 \%$ and euthyroidism was $80.33 \%$ of various depressive disorders and was more common in females than in males and equal in distribution in both the rural and urban population.

\section{CONCLUSIONS}

Hypothyroidism was found to have been associated with various depressive disorders, cognitive function and psychosis among female patients and hyperthyroidism was associated with psychosis, anxiety, depression and cognitive impairment.

\section{KEY WORDS}

Depression, Hypothyroidism, Hyperthyroidism, Euthyroidism
Corresponding Author: Dr. M. Padma Geetanjali, Professor and HOD, Department of Physiology, Government Medical College, Srikakulam, Andhra Pradesh, India.

E-mail:gmpadma@yahoo.com

DOI: $10.14260 / j e m d s / 2021 / 609$

How to Cite This Article: Gupta SVB, Geetanjali MP, Devi LBK. Study of thyroid function in patients of Srikakulam, Andhra Pradesh, who were suffering from various depressive disorders. J Evolution Med Dent Sci 2021;10(35):2980-2984, 10.14260/jemds/2021/609

Submission 26-05-2021,

Peer Review 22-07-2021,

Acceptance 28-07-2021,

Published 30-08-2021.

Copyright (C) 2021 JEMDS. This is an open access article distributed under Creative Commons Attribution License [Attribution 4.0 International (CC BY 4.0)] 


\section{BACKGROUND}

Thyroid disorder patients are more prone to develop depressive symptoms. Depression is also associated with various thyroid abnormalities. ${ }^{1}$ The disturbances in thyroid hormone levels affect mental status, emotion and cognition. A slight change in thyroid hormone levels even within the normal range, affects cerebral function, alteration in mood, behaviour and cognition. There are symptoms of depression, anxiety, increasing fatigability and psychomotor slowing.

The depressive symptoms are more in elderly patients with rapid changes in thyroid hormone levels. ${ }^{1}$ Adults with frank thyroid disease show mental symptoms like depression, anxiety and reversible cognitive decline. The prevalence of thyroid dysfunction appears to be greater in bipolar mood disorder. ${ }^{1}$ In depressive disorder patients, $1 \%$ to $4 \%$ have primary (overt hypothyroidism) and $4 \%$ to $40 \%$ have subclinical hypothyroidism. ${ }^{2}$

Overt thyroid dysfunction is usually mild. Thyroid abnormality is not a causal factor, it is mainly a risk factor for depression. ${ }^{2}$ The most common abnormalities are the upper range of normal or slightly elevated serum T4, low serum T3 and elevated serum TSH level in depressive disorder patients. $^{2}$

\section{Objectives}

- To study the thyroid function in various depressive disorders at the Department of Psychiatry, Government medical college, Srikakulam, Andhra Pradesh state.

- To assess the thyroid function following the investigation of serum TSH, T3 and T4 in patients with various depressive disorders and analyse and correlate the data on various parameters like age (21 - 30, 31 - 40, 41 - 50, 51 - 60 yrs.), sex (male and female), locality (rural and urban) etc.

\section{METHODS}

In this observational study, 61 cases of diagnosed depressive disorder patients of 21 to 60 years age group, both males and females of rural and urban areas, who attended the outpatient and inpatient department of Psychiatry, Government medical college Srikakulam, were selected for the study of thyroid function. This prospective study was done from July 2018 to June 2019 following informed consent from patients and permission from the institutional ethical committee.

\section{Inclusion Criteria}

1. Patients diagnosed with various depressive disorders.

2. Informed consent by the patients for the study.

3. Patients should have at least one informant.

4. Both male and female patients of 21-to-60-year age group.

\section{Exclusion Criteria}

1. Patients who were already on thyroid medication.

2. Patients who were unwilling and uncooperative to participate in the study.

3. Patients with major physical illnesses (hypertension and diabetes)

4. History of thyroid surgery.

\section{Statistical Analysis}

It was done by using SPSS 20.0 for windows evaluation and found

1. One-way ANOVA test with P-value $<0.01$, statistically significant.

2. One-tailed Test with $\mathrm{z}$ score and P-value $<0.01$, statistically significant.

3. Frequency and percentage found with different parameters like age, sex, locality of depressive disorder patients vs thyroid status.

\section{RESULTS}

In this study, 61 cases were selected for the study of thyroid function according to the international classification of the diseases - ICD 10 criteria, i.e.

1. Minor or mild depression,

2. Moderate depression,

3. Major depression,

4. Severe depression,

5. Recurrent depression,

6. Depression with psychosis

7. Dysthymia and

8. Bipolar depression.

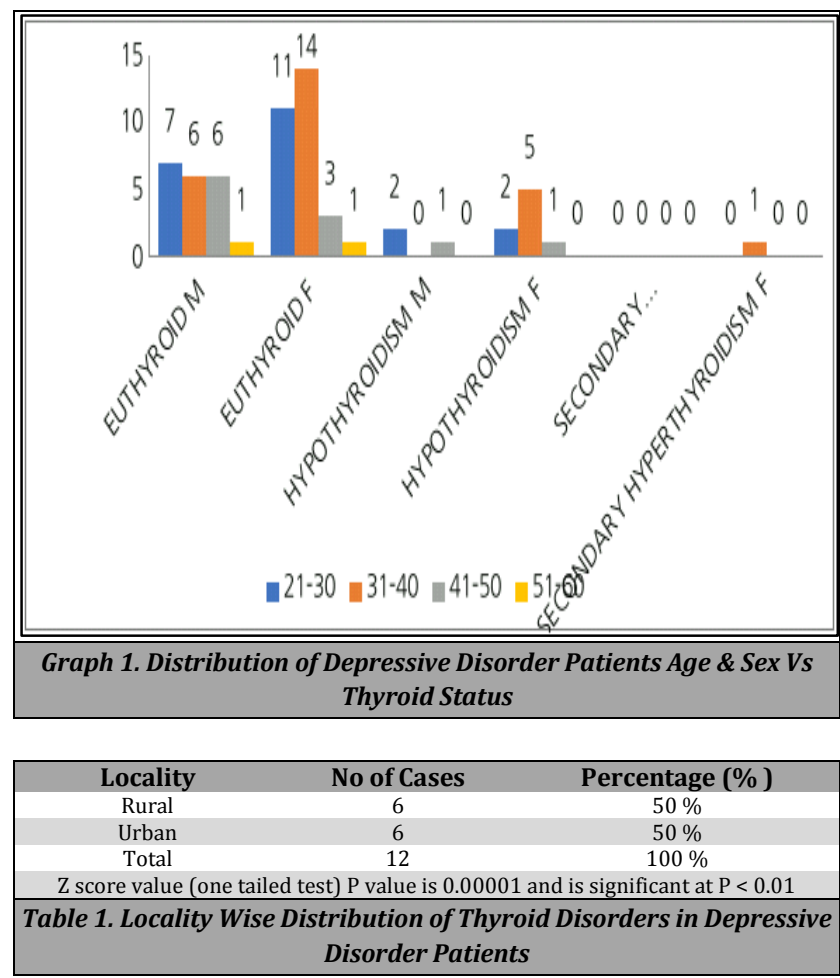




\begin{tabular}{|c|ccccc|}
\hline $\begin{array}{c}\text { Mean and SD Values of } \\
\text { TSH, T4, T3 }\end{array}$ & T3 ng/dl & T4 ug/dl & TSH ulu/ml \\
Euthyroid Status N= 49 & Mean & 109.5167 & 7.7779 & 2.3867 \\
& St Dev & 27.0402 & 1.9351 & 0.9945 \\
Hypothyroid Status N = 11 & Mean & 113.0227 & 7.8327 & 7.2472 \\
& SD & 31.66809 & 1.2045 & 3.2148 \\
Hyperthyroid Status N = 1 & Mean & 127.54 & 12.7 & 6.07 \\
Total Abnormal Thyroid & SD & 0 & 0 & 0 \\
Status N = 12 & MD & 114.2325 & 8.2383 & 7.1491 \\
Total Thyroid Status N = 61 & Mean & 30.4837 & 1.8147 & 3.0839 \\
& SD & 27.5447 & 7.8685 & 3.3236 \\
\hline Table 2. Mean and Standard Deviation Values of TSH, T4, T3 Values \\
\hline
\end{tabular}

\begin{tabular}{|c|c|c|c|}
\hline Type & $\begin{array}{c}\text { T4 / T3 } \\
\text { Level }\end{array}$ & $\begin{array}{c}\text { No of } \\
\text { Patients }\end{array}$ & $\%$ \\
\hline High TSH (Primary Hypothyroidism) & Normal & 1 & $1.63 \%$ \\
\hline High TSH (Subclinical Hypothyroidism) & Normal & 10 & $16.39 \%$ \\
\hline High TSH (Secondary Hyperthyroidism) & High & 1 & $1.63 \%$ \\
\hline Normal TSH (Euthyroidism) & Low T4 & 3 & $4.91 \%$ \\
\hline Normal TSH (Euthyroidism) & High T4 & 1 & $1.63 \%$ \\
\hline Normal TSH (Euthyroidism) & Low T4 and T3 & 1 & $1.63 \%$ \\
\hline \multirow[t]{2}{*}{ Normal TSH (Euthyroidism) } & $\begin{array}{l}\text { Normal T4 and } \\
\text { Normal T3 }\end{array}$ & 44 & $72.13 \%$ \\
\hline & Total & 61 & $100 \%$ \\
\hline $\begin{array}{c}\text { ion of TSH, T4, } \\
\text { Depressive Di }\end{array}$ & $\begin{array}{l}\text { - Thyroid Ab } \\
\text { order Patients }\end{array}$ & mal & atus in \\
\hline
\end{tabular}

\begin{tabular}{|c|c|c|c|c|}
\hline 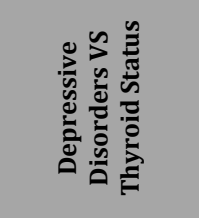 & 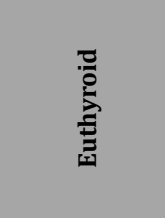 & 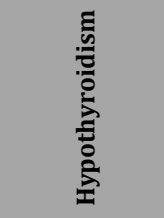 & 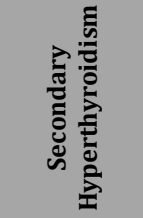 & $\stackrel{\pi}{0}$ \\
\hline $\begin{array}{l}\text { Mixed Anxiety } \\
\text { Depression }\end{array}$ & $\mathrm{N}=10,16.39 \%$ & $\mathrm{~N}=2,3.27 \%$ & $\mathrm{~N}=0,0 \%$ & $\mathrm{~N}=12,19.67 \%$ \\
\hline $\begin{array}{l}\text { Depression with } \\
\text { Psychosis }\end{array}$ & $\mathrm{N}=5,58.19 \%$ & $\mathrm{~N}=2,3.27 \%$ & $\mathrm{~N}=1,1.63 \%$ & $\mathrm{~N}=8,13.11 \%$ \\
\hline $\begin{array}{l}\text { Bipolar Depression } \\
\text { Mild Depression }\end{array}$ & $\begin{array}{c}N=13,21.31 \% \\
N=5,58.19 \%\end{array}$ & $\begin{array}{c}\mathrm{N}=0,0 \% \\
\mathrm{~N}=1,1.63 \%\end{array}$ & $\begin{array}{l}\mathrm{N}=0,0 \% \\
\mathrm{~N}=0,0 \%\end{array}$ & $\begin{array}{c}N=13,21.31 \% \\
N=6,9.83 \%\end{array}$ \\
\hline $\begin{array}{l}\text { Moderate } \\
\text { Depression }\end{array}$ & $\mathrm{N}=3,4.91 \%$ & $\mathrm{~N}=2,3.27 \%$ & $\mathrm{~N}=0,0 \%$ & $\mathrm{~N}=5,58.19 \%$ \\
\hline Severe Depression & $\mathrm{N}=5,58.19 \%$ & $\mathrm{~N}=1,1.63 \%$ & $\mathrm{~N}=0,0 \%$ & $\mathrm{~N}=6,9.83 \%$ \\
\hline $\begin{array}{c}\text { Recurrent } \\
\text { Depression }\end{array}$ & $N=5,58.19 \%$ & $\mathrm{~N}=3,4.91 \%$ & $\mathrm{~N}=0,0 \%$ & $\mathrm{~N}=8,13.11 \%$ \\
\hline Dysthymia & $\mathrm{N}=3,4.91 \%$ & $\mathrm{~N}=0,0 \%$ & $\mathrm{~N}=0,0 \%$ & $\mathrm{~N}=3,4.91 \%$ \\
\hline Total & $\mathrm{N}=49,80.32 \%$ & $\mathrm{~N}=11,18.03 \%$ & $\mathrm{~N}=1,1.63 \%$ & $\mathrm{~N}=61,100 \%$ \\
\hline Mean & 6.125 & 1.375 & 0.125 & 2.542 \\
\hline Standard Deviation & 3.5229 & 1.0607 & 0.3536 & 3.336 \\
\hline Degree of freedom & \\
\hline $\begin{array}{l}\text { ANOVA test and P } \\
\text { Value }\end{array}$ & \multicolumn{4}{|c|}{ F Ratio Value $=17.60523$ and $P$ value is 0.000032} \\
\hline \multicolumn{5}{|c|}{$\begin{array}{c}\text { Table 4. Distribution of Depressive Disorders Vs Thyroid Status } \\
\text { (Frequency \& Amp; Percentage) }\end{array}$} \\
\hline
\end{tabular}

One way ANOVA test report for serum TSH values showed a degree of freedom $1, \mathrm{f}$ ratio value as 81.60978 , P-value as 0.00001 and was significant at $\mathrm{P}<0.01$, so statistically significant.

Thyroid function tests (serum T3, T4 and TSH) were performed on all depression patients. Venous blood samples were drawn for the measurements of serum TSH, Thyroxine (T4) and Triiodothyronine (T3) after overnight fasting. Serum TSH, T4 and T3 levels were analysed by CLIA (Chemiluminescent Immunoassay) using ASSES 2 and UniCel Dxl 600 automated systems.

In this present study, out of 61 cases of depressive disorder patients, a total of 12 cases with serum TSH level 0.66 to $16.05 \mathrm{uIU} / \mathrm{ml}$, serum T4 level - 2 to $13 \mathrm{ug} / \mathrm{dl}$, serum T3 level - 43 to $186.4 \mathrm{ng} / \mathrm{dl}$ with normal biological reference ranges biochemistry lab as follows: a) Serum TSH: 0.27 to $4.50 \mathrm{uIU} / \mathrm{ml}$, b) Serum T4: 5.132 to $14.06 \mathrm{ugs} / \mathrm{dl}, \mathrm{c}$ ) Serum T3: $84.6 \mathrm{ng} / \mathrm{dl}$ to $200 \mathrm{ng} / \mathrm{dl}$ respectively.

In this study, TSH $>4.50 \mathrm{uIU} / \mathrm{ml}$, with $\mathrm{T} 4<5.132 \mathrm{ug} / \mathrm{dl}$ was considered as clinically significant hypothyroidism while
TSH $<0.27$ uIU / ml was considered as clinically significant hyperthyroidism.

With reference to Graph 1, out of total depressive disorder patients $\mathrm{N}=61$ (100\%), according to age distribution it was found as follows i.e., 1. 21 - 30 yrs. age $\mathrm{N}=$ $22(36.06 \%), 31-40$ yrs. $\mathrm{N}=26(42.62 \%), 41-50$ yrs. $\mathrm{N}=$ $11(18.03 \%)$ and $51-60$ yrs. $\mathrm{N}=2(2.27 \%)$ and thyroid status in sex wise as follows

1. Euthyroidism male $\mathrm{N}=20(32.78 \%)$,

2. Euthyroidism female $\mathrm{N}=29(47.54 \%)$

3. Hypothyroidism male $\mathrm{N}=3(4.91 \%)$,

4. Hypothyroidism female $\mathrm{N}=8(13,11 \%)$,

5. Secondary hyperthyroidism male $\mathrm{N}=0(0 \%)$,

6. Secondary hyperthyroidism female $N=1(1.63 \%)$.

It was found that abnormal thyroid status was more in 31 to 40 years age group mainly in females i.e., $\mathrm{N}=5(8.91 \%)$. The sex-wise distribution of thyroid disorders in depressive disorder patients showed male $\mathrm{N}=3(25 \%)$ and female $\mathrm{N}=9$ (75) out of total abnormal thyroid status $N=12$ (100\%) and sex-wise distribution of male to female was 1: 3 ratio and $\mathrm{z}$ score value of one-tailed test with p-value was $0.00001, \mathrm{P}<$ 0.01 , so considered statistically significant.

With reference to Table 1, shows locality distribution of thyroid disorders in depressive disorder patients total $\mathrm{N}=12$ $(100 \%)$, rural $\mathrm{N}=6(50 \%)$ and urban area $\mathrm{N}=6(50 \%)$ and equal distribution in both rural and urban population and $\mathrm{Z}$ score value (one-tailed test) and found $P$ value as 0.00001 and $\mathrm{P}<0.01$, so considered statistically significant.

With reference to Table 2, the mean and standard deviation values of TSH, T4, T3, out of total thyroid status $\mathrm{N}=$ $61(100 \%)$, euthyroid status $\mathrm{N}=49(80.33 \%)$ and abnormal thyroid status $\mathrm{N}=12(19.67 \%)$. Out of 12 cases, hypothyroid status $\mathrm{N}=11(18.03 \%)$, hyperthyroidism status $\mathrm{N}=1(1.63$ $\%)$ and one way ANOVA test report for serum TSH value showed degree of freedom $1, \mathrm{~F}$ ratio value as $81.60978, \mathrm{P}-$ value as 0.00001 and was significant at $P<0.01$, So statistically significant.

With references to Table 3, shows out of total depressive disorder patients $\mathrm{N}=69$ (100\%), total abnormal thyroid cases $\mathrm{N}=12(19.67 \%)$. Out of that

1. Primary hypothyroidism: $N=1(1.63 \%)$ i.e. With high TSH and normal T3 and T4,

2. Subclinical hypothyroidism cases $N=10$ (16.39 \%) i.e. with high TSH and normal T3 and T4 levels, and

3. Secondary hyperthyroidism $N=1(1.63 \%)$ i.e. high $\mathrm{TSH}$ and high T4 level.

Out of the remaining cases with euthyroidism $N=49(80.33$ $\%)$, all patients were with normal TSH levels. Whereas -

- Low T4 was found in euthyroidism cases $\mathrm{N}=3(4.91 \%)$,

- High T4 in euthyroidism case $\mathrm{N}=1(1.63 \%)$,

- Low T4 and T3 found in euthyroidism cases $\mathrm{N}=1(1.63$ $\%$ ) and

- $\quad$ Normal T4 and T3 found in euthyroidism cases $\mathrm{N}=$ $44(72.13 \%)$

With reference to Table 4, distribution of depressive disorder cases vs thyroid function shows, out of total $\mathrm{N}=$ 61(100\%), mean 2.542 and SD 3.336 and distribution of different depressive disorders are as follows i.e. 1. Mixed anxiety depression $\mathrm{N}=12$ (19.67\%), 2. Depression with psychosis $\mathrm{N}=8(13.11 \%)$, Bipolar depression $\mathrm{N}=13(21.31$ $\%)$, 4. mild depression $\mathrm{N}=6$ (9.83\%), 5. Moderate depression $\mathrm{N}=5(58.19 \%)$, 6. Severe depression $\mathrm{N}=6$ (9.83 
\%), 7. Recurrent depression $N=8$ (13.11\%), 8. Dysthymia N $=3(4.91 \%)$ and the thyroid status as follows, 1 . Euthyroidism total $\mathrm{N}=49$ (80.32\%), mean 6.125 and standard deviation 3.5229 2. Hypothyroidism N = 11 (18.93 $\%)$, mean 1.375 and SD 1.067 and 3. Secondary hyperthyroidism $\mathrm{N}=1(1.63 \%)$ and mean 0.125 and standard deviation 0.3536. ANOVA test was done and degree of freedom was 2 and $F$ ratio value was 17.60523 and $p$ value was 0.000032 i.e., $\mathrm{P}<0.01$, so considered statistically significant and there was equal distribution of abnormal thyroid status in all depressive disorder patients.

As per the statistical analysis mentioned above, depressive disorders are associated with thyroid function abnormalities which are proved statistically significant.

\section{DISCUSSION}

In euthyroidism there is normal production of thyroid hormones (TSH, T4, T3) by the thyroid gland and normal levels in the circulation at a cellular level.

In hyperthyroidism, there is excessive production of thyroid hormone and an increase in circulating and intracellular thyroid hormones (low TSH and high fT4 or fT3). Grave's disease is the most common cause and its clinical features are weight loss despite a good appetite, excessive sweating, irritability, anxiety, tremulousness, palpitation, goitre and proximal muscle weakness. ${ }^{3}$

Hypothyroidism is due to the lack of thyroid hormone production and inadequate replacement therapy. In these cases, serum TSH and fT4 levels are low, and patients suffer from apathy, fatigue, cold intolerance, slow speech, weight gain, coarse features and facial puffiness. 4

Subclinical hypothyroidism (SCHT) is an asymptomatic state. The serum fT3 and fT 4 are normal but serum TSH is slightly elevated. Subclinical hyperthyroidism is also an asymptomatic state and serum fT3 and fT4 are normal and serum TSH level is suppressed. Both conditions are a mild stage of thyroid hypofunction and hyperfunction respectively. ${ }^{5}$

There are various endogenous circadian rhythm abnormalities found in depression like mood variation, fluctuation in core body temperature, cortisol secretion and sleep-wake cycle, abnormal diurnal melatonin secretion and TSH rhythm etc. An absent TSH nocturnal surge has been noted in depression and a low basal TSH is found in major depression.6,7

TRH also acts as an antidepressant. TRH at a dose of 500 ug given IM or IV in women suffering from unipolar depression shows improvement in depression. Chronic TRH hypersecretion leads to downregulation of pituitary TRH receptors and elevated CSF concentration of TRH found in depressive disorder patients. ${ }^{8}$

The prolonged release of TRH in depression was found due to decreased 5HT activity to maintain normal 5HT function and normal levels of thyroid hormones. ${ }^{9}$

The blunted TSH response was seen by, 1 . the hypercortisolism associated with depression 2 . elevated thyroid hormone levels due to adrenergic mechanism. ${ }^{10}$

The treatment for hypothyroidism in depression patients is necessary to reverse the clinical progression, correct metabolic derangements and bring down levels of TSH and serum fT4. Levothyroxine (50 - 20ug / day), liothyronine (25 - 50ug / day) are preferred preparations as they provide the most uniform thyroid replacement. They are used either alone or as an adjuvant along with antidepressant drugs in depressive disorder patients. Usually, they are used in patients who are not responding even after 6 weeks of antidepressant medications. ${ }^{11}$

Subclinical hypothyroidism (SCHT) patients are asymptomatic. Sometimes there is increase in energy, decreased constipation and skin dryness after treatment with thyroid supplementation. Thyroid replacement is indicated in SCHT patients who have

1. Serum TSH level $>10 \mathrm{uIU} / \mathrm{ml}$,

2. A deficit in memory or cognitive functioning

3. Bipolar illness. ${ }^{11}$

Thyroid hormone should be replaced slowly by increasing the dosages, monitored and maintained for 2 months as needed, then tapered gradually as needed at 12.5 ug / day every 3 to 7 days. Monitoring is important to prevent complications due to overdosage of thyroid hormones like transient headache, weight loss, palpitations, nervousness, diarrhoea, abdominal cramps, sweating, tachycardia, hypertension, tremor, insomnia, osteoporosis etc. Monitoring is also important in older than 50 years of patients who are suffering from cardiac disease and avoid precipitating angina, cardiac arrhythmia, acute myocardial infarction, cardiac failure and even death due to overdosage. ${ }^{11}$

Overdosage of thyroid hormone supplementation in depressive disorder patients leads to hyperthyroidism. They should be treated with

- Anti-Thyroid drugs like propylthiouracil, methimazole,

- $\quad$ Radioactive iodine (I - 131),

- Slowly taper thyroid hormone drugs, and

- Finally, surgical thyroidectomy, if necessary, followed by thyroid hormone supplementation.

- $\quad$ Beta-blockers like atenolol (50 - $100 \mathrm{mg} /$ day) are used symptomatically. (Should be used cautiously in patients with asthma).

Tricyclic antidepressant drugs (TCA) like amitriptyline, imipramine act on hypothalamo-pituitary-thyroid axis as follows, a) act on iodine and thyroid peroxidase and deactivate them, thus increasing deiodinase activity b) decrease TSH response to TRH. c) The other antidepressant drugs decrease circulating thyroid hormone levels. Patients who receive TCA should be monitored closely to prevent the development of thyroid function abnormalities. ${ }^{12}$

SSRIs like sertraline, fluoxetine are used as antidepressants in the treatment of MDD and mixed anxiety depression and also indicated for mild to moderate depression. The SSRIs reduce the reabsorption (reuptake) of serotonin by the receptors at the presynaptic membrane and increase the bioavailability of serotonin at the synaptic cleft and bind to the receptors of postsynaptic membrane. SSRIs decrease the dosage of levothyroxine during the treatment of depression due to hypothyroidism. Non-SSRIs i.e., SNRIs (serotonin-norepinephrine reuptake inhibitors) like venlafaxine is effective in mild to moderate depression. ${ }^{13}$ 


\section{CONCLUSIONS}

Thyroid disorders are more common among females, mainly hypothyroidism. Hypothyroidism is associated with

- Various depressive disorders,

- Cognitive dysfunction,

- $\quad$ Psychosis.

Hyperthyroidism is associated with

- Psychosis,

- Anxiety,

- Depression and

- Cognitive impairment.

An attempt was made to study the thyroid function in various depressive disorders and find out the prevalence of thyroid function abnormalities. The results of the study are comparable with other studies and standard books substantiating the findings of the study.

Data sharing statement provided by the authors is available with the full text of this article at jemds.com.

Financial or other competing interests: None.

Disclosure forms provided by the authors are available with the full text of this article at jemds.com.

\section{REFERENCES}

[1] Hall RCW, Hall RCW. Anxiety and endocrine disease. Seminars in Clinical Neuropsychiatry 1999;4(2):72-83.

[2] Wolkowitz OM, Rothschild AJ. Psycho neuroendocrinology: the scientific basis of clinical practice. $1^{\text {st }}$ edn. Washington, DC, USA: American Psychiatric Press 2003.

[3] Practice Guidelines for Thyroid Disorders. The Malaysian Consensus 2000.
[4] Fabrizio M. Classification of Thyroid diseases: suggestion for a revision. J Clin Endocrinol Metab 2003;88(4):142832.

[5] Bjoro T, Holmen J, Kruger 0, et al. Prevalence of thyroid disease, thyroid dysfunction and thyroid peroxidise antibodies in a large, unselected population. The Health study of Nord-Trondelag (HUNT). Eur J Endocrinol 2000;143(5):639-47.

[6] Souetre E, Salvati E, Wher TA, et al. $24 \mathrm{hr}$ of profiles of body temperature and plasma TSH in bipolar patients during depression and during remission and in normal control subjects. American Journal of Psychiatry 1988;145(9):1133-7.

[7] Poirier MF, Loo H, Galinowski A, et al. Sensitive assay of thyroid stimulating hormone in depressed patients. Psychiatric Research 1995;57(1):41-8.

[8] Hinkle PM, Tashjain AH Jr. Thyrotropin-releasing harmone regulates the number of its own receptors in the GH3 strain of pituitary cells in culture. Biochemistry 1975;14(17):3845-51.

[9] Duval F, Mokrani MC, Bailey P, et al. Thyroid axis activity and serotonine function in major depressive episode. Psychoneuroendocrinology 1999;24(7):695-712.

[10] Duval F, Mokrani MC, Crocq MA, et al. Influence of thyroid hormones on morning and evening TSH response to TRH in major depression. Biological Psychiatry 1994;35(12):926-34.

[11] Benjamin JS, Virginia AS, Pedro R, et al. Kaplan \& Sadock's Synopsis of Psychiatric behavioral sciences / Clinical psychiatry. $11^{\mathrm{TH}}$ edn. New York: Lippincott Williams \& Wilkins 2009: p. 1039-40.

[12] Krishna B, Prasanth YM. A study of thyroid dysfunction among patients with major depressive disorders at tertiary care centre in Mangalore. IOSR-J Dental and Medical Sciences 2016;15(6):115-8.

[13] Barrett KE, Barman SM, Boitano S, et al. Ganong's Review of Medical Physiology. 25th edn. (Lange Medical Book) McGraw-Hill Education / Medical 2015: p. 152. 